\title{
RANCANG BANGUN APLIKASI STEGANOGRAPHY METODE MINIMUM ERROR LEAST SIGNIFICANT BIT REPLACEMENT(MELSBR)
}

\author{
I. Aprilia1', D. Ariyanti² dan A. Izzuddin ${ }^{3}$ \\ 1,2,3Program Studi Teknik Elektro Fakultas Teknik Universitas Panca Marga Prooblinggo \\ JI. Yos Sudarso No. 107 Pabean Dringu Probolinggo 67271 \\ 1Ira.aprilia11@upm.ac.id, 2dekd19@yahoo.com, 3ahmad.izzuddin@upm.ac.id
}

\begin{abstract}
Digital data security today is an important part of user because of the increasingly widespread misuse of individuals who can easily open a personal thing. In this case, steganography is a technique that discusses the security of digital data information through the technique of hiding data into other data. Many methods are used in steganography techniques in the process of hiding digital data information. But in this study, the author uses the steganography method based on the insertion of files in the form of files, namely in this case * txt file using the Minimum Error Least Significant Bit Replacement (MELSBR) method with a media storage in the form of 24-bit bitmap files and data that can be inserted in the form of files * txt. The nature of the MELSBR method is to adapt to the local characteristics of the storage medium. In the process of image processing testing researchers use PSNR parameters to determine the quality comparison of digital images before and after processing. The results of this study, concealment and insertion using the MELSBR method with PSNR testing has a greater value so that it can be concluded that the image after processing is getting closer to the cover image.
\end{abstract}

Keyword : : Image Processing, Minimum Error Least Significant Bit Replacement (MELSBR), Steganography.

\section{ABSTRAK}

Keamanan data digital dewasa ini adalah salah satu bagian penting dari penggunaan komputer karena semakin maraknya penyalahgunaan oknum-oknum yang dapat membuka dengan mudah suatu hal yang bersifat pribadi. Dalam hal ini, steganografi merupakan teknik yang membahas mengenai pengamanan infromasi data digital lewat teknik penyembunyian data kedalam data yang lainnya. Banyak metode yang digunakan dalam teknik steganography dalam proses penyembunyian informasi data digital. Namun pada penelitian ini, Penulis menngunakan metode steganography berdasarkan penyisipan file berupa berkas yaitu dalam hal ini file *txt dengan mengggunaka metode Minimum Error Least Significant Bit Replacement (MELSBR) dengan penampungan media yang berupa berkas bitmap 24 bit serta data yang dapat disisipkan berupa berkas *txt. Sifat dari metode MELSBR ini adalah beradaptasi dengan karakteristik lokal dari media penampung. Pada proses pengujian pemrosesan citra peneliti menggunakan parameter PSNR untuk mengetahui perbandingan kualitas citra digital sebelum dan sesudah diproses. Adapun hasli dari penelitian ini, penyembunyian serta penyisipannya menggunakan metode MELSBR dengan pengujian PSNR bernilai semakin besar sehingga dapat disimpulkan bahwa citra setelah diproses semakin mendekati citra slinya.

Keyword $\quad$ : Citra digital, Minimum Error Least Significant Bit Replacement (MELSBR), Steganografi. 


\section{LATAR BELAKANG}

\subsection{Latar Belakang}

Pada era sekarang ini, semakin berkembangnya teknologi komputer maka semakin marak pula kegiatan saling bertukar informasi, data dan pesan bagi penggunaan komputer di dunia ini dengan hal-hal yang bersifat pribadi. Salah satu bagian terpenting dalam teknologi internet yaitu keamanan informasi data digital agar tidak terjadi suatu penyalahgunaan oknumoknum yang tidak bertanggung jawab. Keamanan merupakan bagian dari perlindungan informasi yang dapat mengamankan data dari penyerang yang ingin mencuri informasi data. Dalam hal ini, sistem keamanan memiliki dua bagian yang kriptografi dan penyembunyian informasi [1]. Adapun cara yang digunakan dalam keamanan data digital yaitu dengan menggunakan teknik steganografi. Steganografi merupakan seni untuk menyembunyikan pesan di dalam media digital sedemikian rupa, sehingga orang lain tidak menyadari ada suatu pesan di dalam media tersebut. Steganografi membutuhkan dua properti yaitu wadah penampug dan data rahasia yang disembunyikan [2].

Metode yang terdapat pada teknik steganografi ini banyak sekali yang bisa digunakan dalam penyembunyian pesan. Metode lain yang dikembangkan dalam penelitian ini adalah metode MELSBR. Metode ini pertama kali diperkenalan oleh Yeuan-Keun Lee dan Ling-Hwein Chen dimana dalam makalahnya mengenai An Adaptive Image Steganographic Model Based on Minimum-Error LSB Replacement. Metode MELSBR yang diterapkan pada citra berwarna (bitmap 24-bit) memiliki beberapa langkah atau tahapan utama untuk melakukan proses penyisipan, antara lain Capacity Evaluation, Minimum Error Replacement dan Error Diffusion [3]. Adapun gambaran umum dari metode yang diajukan adalah seperti pada Gambar 1.

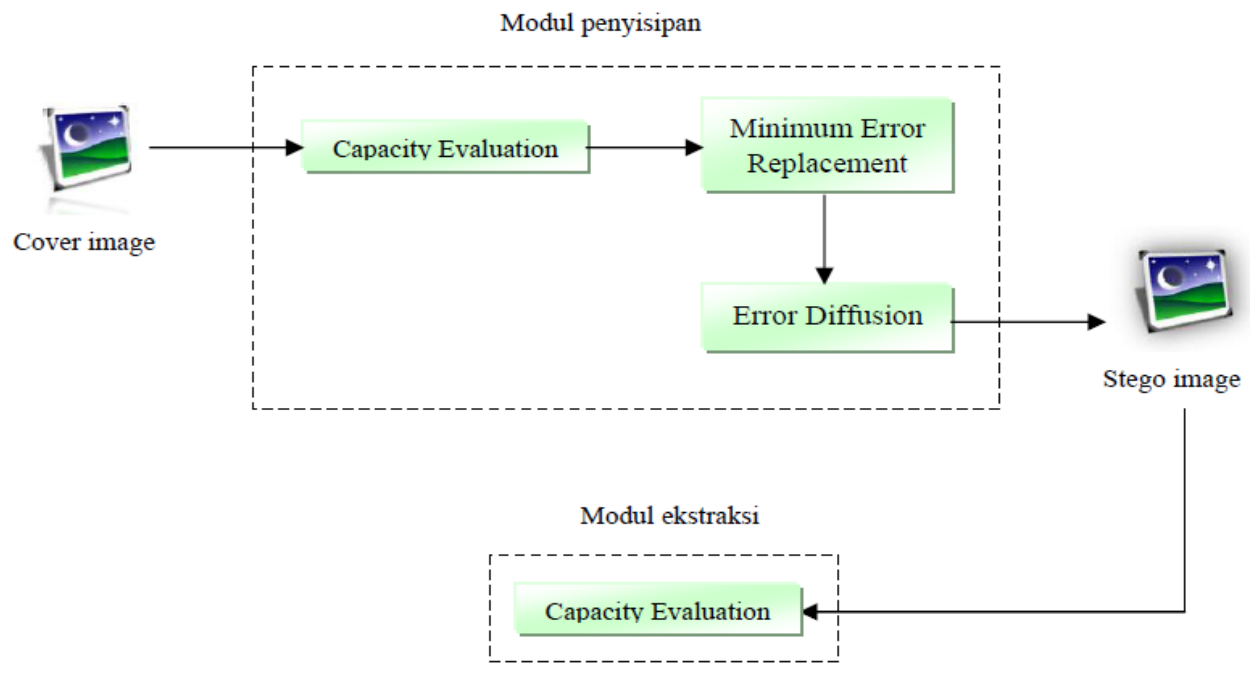

Gambar 1 : Gambaran Umum MELSBR [2] 
Proses pengujian dalam penelitian ini dilkukan dengan perhitungan PSNR digunakan untuk membandingkan kualitas citra hasil dengan citra asal. Semakin tinggi nilai PSNR maka semakin bagus kualitas citra tersebut [4].

Permasalahan yang akan diangkat oleh peneliti yaitu mengimplementasikan algoritma yang ada dalam kasus penyembunyian pesan rahasia dalam citra digital dengan merancang bangun aplikasi steganografi. Dalam kasus penelitian ini, akan dilakukan proses penyembunyian pesan digital dengan media penampung suatu berkas file gambar berupa bitmap 24 bit dengan penyisipan file berupa *text dengan menggunakan Metode MELSBR dengan pengujian PSNR membandingkan citra asli dengan stego image yang sudah diperoleh dari hasil penyisipan file text.

\title{
1.2. Batasan Masalah
}

Citra digital yang digunakan sebagai media penyembunyian data adalah citra bitmap ( ${ }^{*}$.bmp) 24 bit serta penyisipan file berupa text menggunakan metode MELSBR dengan pengujian PSNR.

\author{
II. METODE PENELITIAN \\ 1. Identifikasi Masalah \\ 2. Penetapan Tujuan \\ 3. Pengumpulan beberapa data dari berbagai sumber yang ada \\ 4. Analisa Sistem \\ 5. Perancangan Sistem \\ 6. Implementasi \\ 7. Pengujian PSNR \\ 8. Kesimpulan dan Saran
}

\section{HASIL DAN PEMBAHASAN}

\subsection{Perancangan Sistem}

Perancangan sistem aplikasi dalam penelitian ini dapat disajikan pada Gambar 2 yaitu langkah-langkah penelitian menggunakan metode waterfall. Berikut ini akan dijelaskan tentang pengimplementasian dari analisis dan perancangan yang telah dilakukan terhadap aplikasi steganografi ini. Implementasi penelitian ini yaitu menerjemahkan teori teknik steganografi menggunakan metode MELSBR dalam melakukan proses penyisipan berkas dengan format file (.txt) sebagai berkas yang akan disisipi, media gambar dengan format file (.bmp) sebagai media penampung dan melakukan ekstraksi berkas dengan memasukan stego image hasil proses penyisipan untuk mendapatkan kembali berkas yang disisipi kedalam bentuk coding program Matlab 2016. 


\subsubsection{Proses Encode}

Dalam tahap ini disajikan pada diagram alir gambar 3. Tahapan dalam proses encode yaitu :

1. Input file gambar

Dengan memasukkan file gambar berupa (.bmp)

2. Verifikasi file gambar

Setalah dilakukan penginputan file akan dproses verifikasi gambar (.bmp)

3. Input berkas file

Memasukkan berkas yang akan disisipkan berupa file text

4. Verifikasi berkas file

Melakukan verifikasi berkas file text yang sudah di inputkan

5. Proses Steganografi

Proses Steganografi diproses dengan menggunakan metode MELSBR

6. Selesai

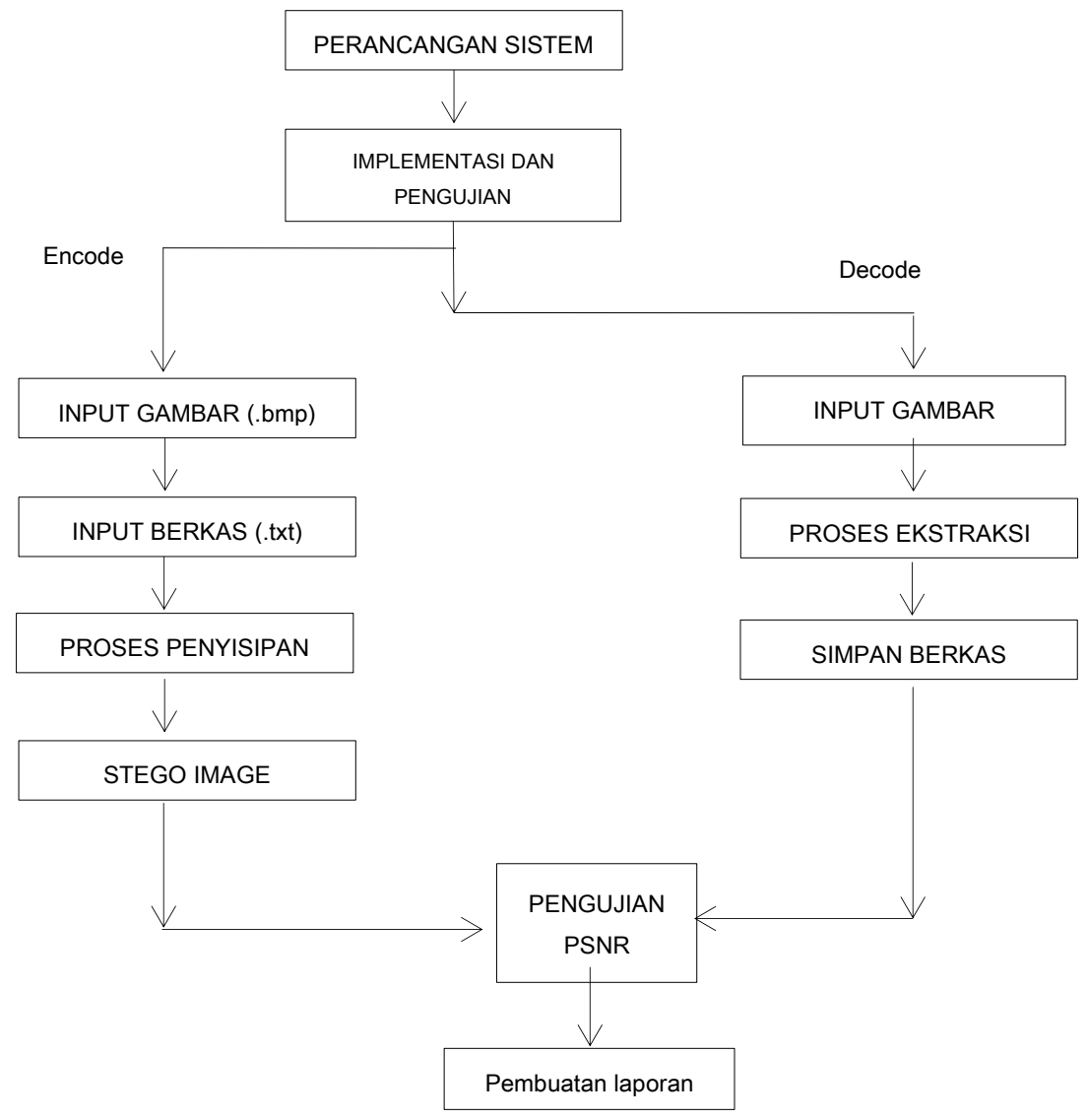

Gambar 2 : Diagram Alir Perancangan sistem 


\subsubsection{Proses Decode}

Sedangkan tahap proses ini dapat disajikan pada gambar 4 yaitu diagram alir proses decode. Adapun tahapannya sebagai berikut :

1. Input file gambar

Memasukkan file gambar yang berupa stego image yang sudah disisipkan file text tadi yang sudah tersimpan dengan format (.bmp)

2. Verifikasi file gambar

Dilakukan proses verifikasi gambar harus berformat (.bmp) dalam penyimpanannya

3. Proses Steganografi

Proses ini merupakan pengembalian berkas file text dengan menggunakan teknik steganografi metode MELSBR

4. Selesai

Penyembunyian pesan berhasil disembunyikan sehingga keluaran dari proses ini adal berkas berformat text. 


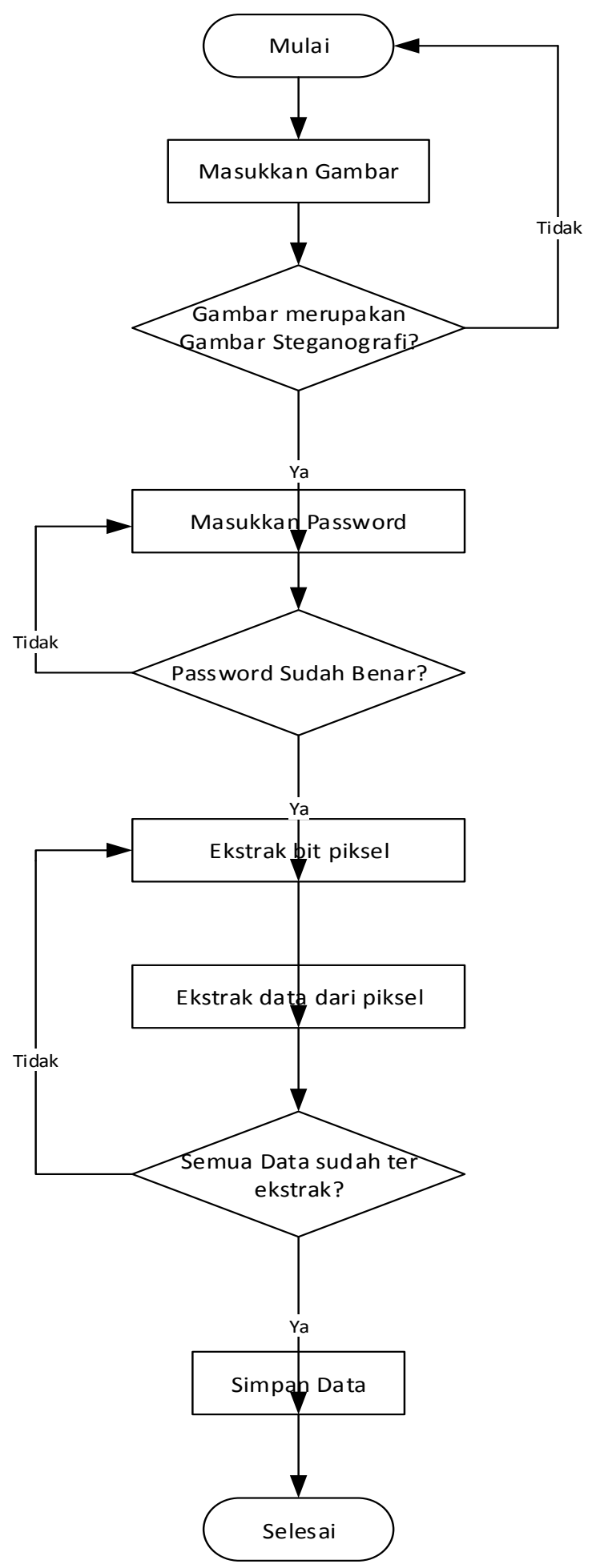

Gambar 3 : Diagram alir Encode 


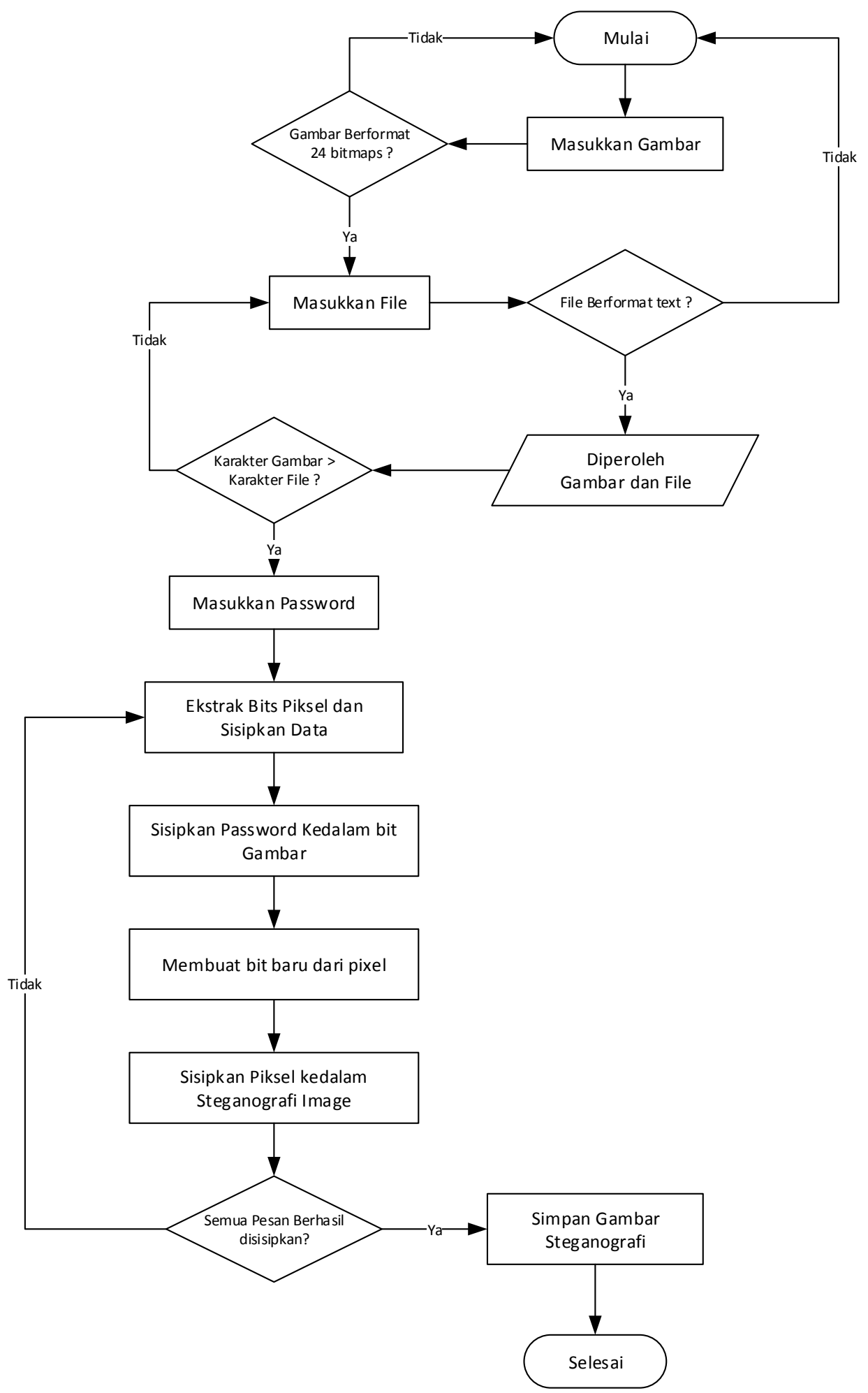

Gambar 4 : Diagram alir Decode 


\subsubsection{Proses Pengujian}

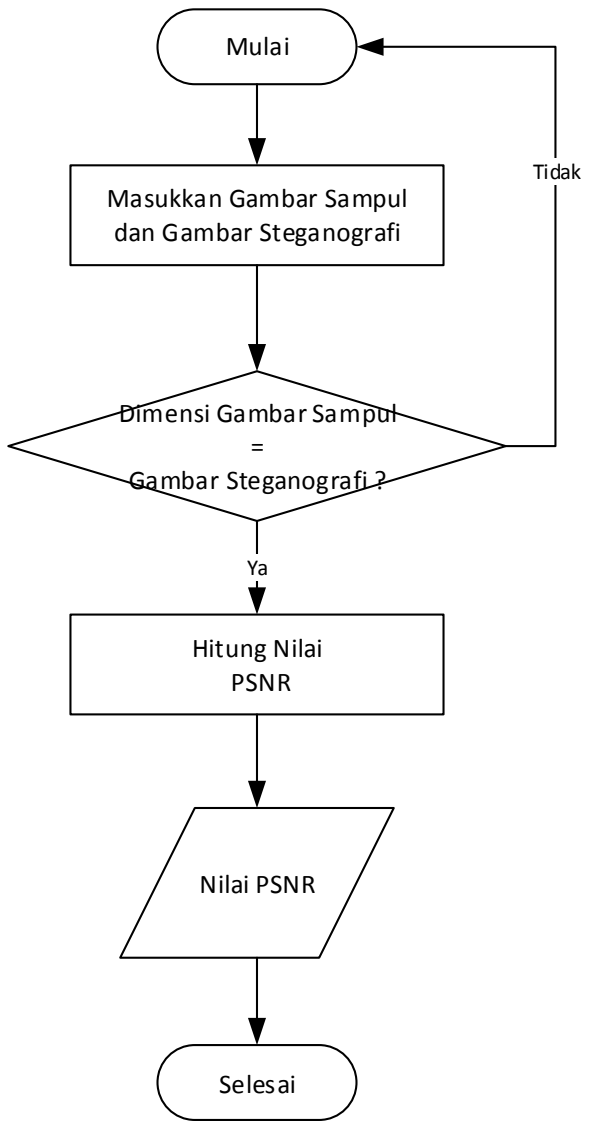

Gambar 5 : Diagram alir pengujian PSNR

\subsection{Implementasi dan Pengujian}

Proses implementasi penelitian ini, berisi tampilan hasil dari penerapan sistem aplikasi yang telah dirancang dengan menerjemahkan teknik steganografi dengan menggunakan metode MELSBR dalam peyisipan berkas file text dan pengembalian berkas. Adapun tampilan aplikasi yang telah dibuat dengan menggunakan bahasa pemograman Matlab 2016 yaitu dapat disajikan pada gambar 6 dengan proses decode dan gambar 7 dengan proses encode. 


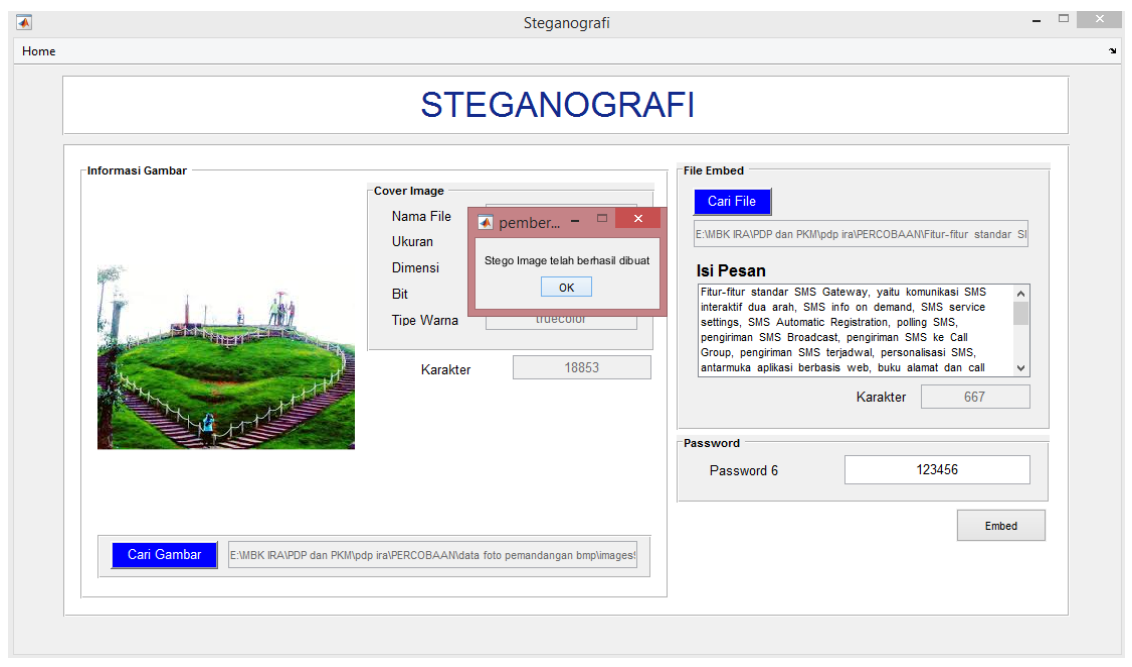

Gambar 6 : Proses Encode

Pada Gambar 6 proses encode ini, menunjukkan bagaimana cara menggunakan encoding dengan memasukkan gambar citra asli serta input file text dengan menggunakan pasword 6 karakter sesuai pengguna untuk menverifikasi gambar asli sudah tersisipkan apa belum kemudian dilakukan proses mengklik tombol embeding untuk mengetahui berhasli tidaknya proses stego imagenya.

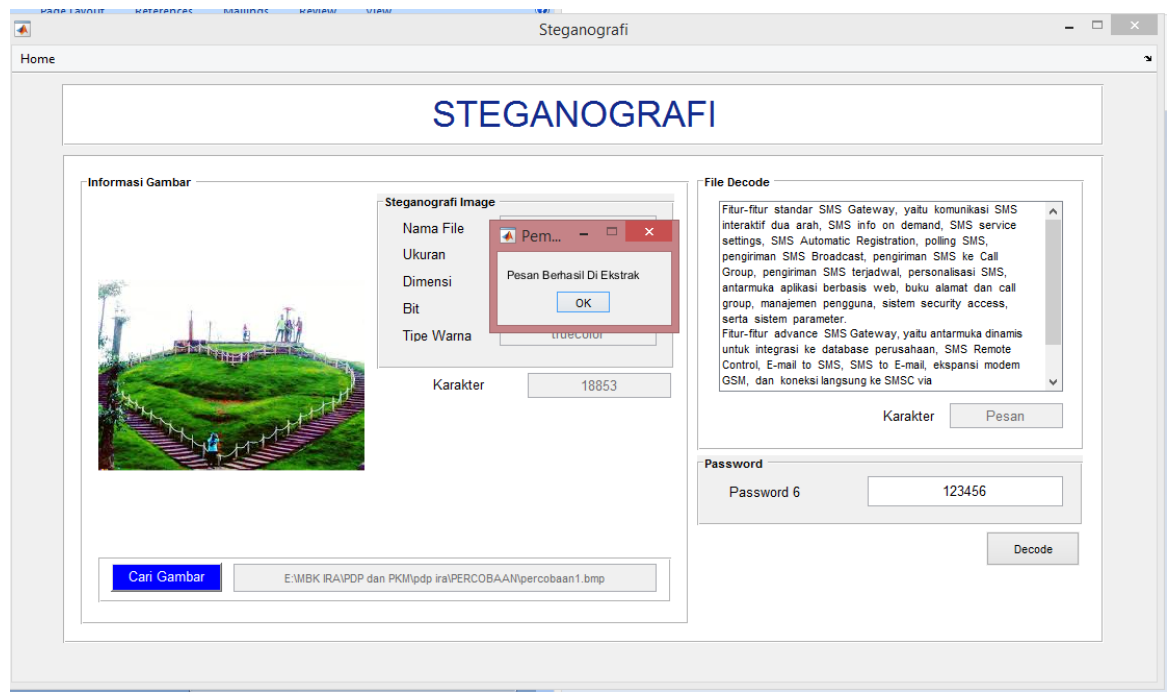

Gambar 7 : Proses Encode

Sedangkan gambar 3 yaitu proses decode memperlihatkan bagaimana cara penggunaan decoding sehingga diperoleh hasli ekstraksi yang terverifikasi dan kemudian dari 
hasil pengujiannya menggunakan parameter PSNR dengan membandingkan citra asli dengan stego image sehingga akan diketahui kualitas distorsi citranya.

\subsection{Pembahasan}

Tabel 1 : Perbandingan gambar cover image dengan stego image yang sudah disisipkan file text.

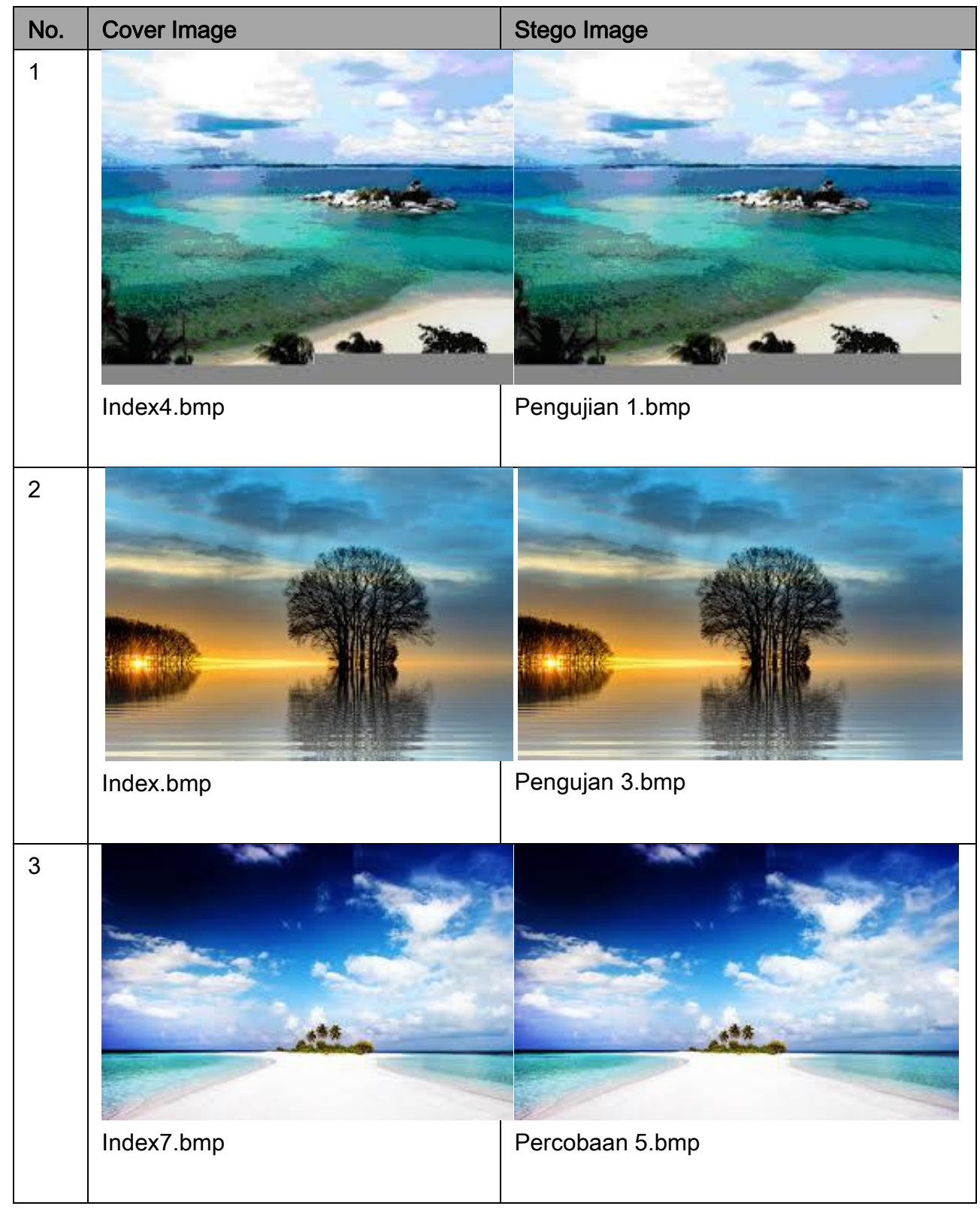


Dari hasil Tabel 1 Diperlihatkan citra asli dengan citra yang sudah disisipkan file berkas text, ternyata secara kasat mata tidak mengalami perbedaan yang mencolok dan bisa dikatakan hampir mirip dengan citra aslinya. Oleh karena itu untuk mengetahui perbandingannya antara citra asli dengan citra yang sudah disisipkan oleh berkas file text. Maka perlu dilakukan perbandingan pengujian dengan menggunakan parameter PSNR untuk mengetahuii kualitas distorsi citra hasil dari penyisipan file text tersebut. Berikut disajikan tabel 2. nilai pengujian hasil PSNR dari citra asli dengan citra yang sudah disisipkan oleh file text dengan penyembunyiaan data citra bitmap (*bmp) 24 bit dengan menggunakan metode MELSBR dengan gambar cover image dan stego image yang disajikan pada Tabel 1.

Tabel 2. Nilai pengujian PSNR dari citra asli dan stego image.

\begin{tabular}{|c|c|c|c|c|c|}
\hline $\begin{array}{l}\text { Cover } \\
\text { image }\end{array}$ & File Pesan & Ukuran & Stego image & Ukuran & $\begin{array}{l}\text { Rata- } \\
\text { rata } \\
\text { PSNR }\end{array}$ \\
\hline Index4.bmp & $\begin{array}{l}\text { Fitur-fitur } \\
\text { standar SMS } \\
\text { Gateway.txt }\end{array}$ & $\begin{array}{l}152234 \\
\text { byte }\end{array}$ & $\begin{array}{l}\text { Pengujian } \\
\text { 1.bmp }\end{array}$ & $\begin{array}{l}152150 \\
\text { byte }\end{array}$ & 95,7525 \\
\hline Index.bmp & $\begin{array}{l}\text { Fitur-fitur } \\
\text { standar SMS } \\
\text { Gateway.txt }\end{array}$ & $\begin{array}{l}150834 \\
\text { byte }\end{array}$ & Pengujan 3.bmp & $\begin{array}{l}150750 \\
\text { byte }\end{array}$ & 95,5871 \\
\hline Index7.bmp & $\begin{array}{l}\text { Fitur-fitur } \\
\text { standar SMS } \\
\text { Gateway.txt }\end{array}$ & $\begin{array}{l}150942 \\
\text { byte }\end{array}$ & $\begin{array}{l}\text { Percobaan } \\
\text { 5.bmp }\end{array}$ & $\begin{array}{l}150858 \\
\text { byte }\end{array}$ & 95.1174 \\
\hline
\end{tabular}

Diperlihatkan pada Tabel 2 yaitu file cover image beserta nama file pesan yang berupa txt dengan file yang sama namun dengan membedakan cover image dan ukuran yang berbeda. Hasil dari stego image yang telah disisipkan pesan file text di atas dengan format hasil stego image berupa (.bmp) dengan menghasilkan ukran yang tidak jauh berbeda dengan cover image. Rerata PSNR bernilai besar dan hampir sama yaitu $95 \mathrm{db}$.

\section{KESIMPULAN}

Penyembunyian pesan dengan media penamoung berupa gambar bitmap dengan penyisipan file text dengan menngunakan Metode MELSBR ternyata dapat disimpulkan metode yang digunakan oleh peneliti ini baik. Sistem implememtasi dari hasil perbandingan citra asli dengan stego image tidak mengalami perbedaan yang mencolok sehingga penyembunyian pesan tersebut dapat dikatakan berhasil dengan baik karena tidak terlihat adanya pesan rahasia yang tersembunyi. Dalam pengujian menggunakan parameter PSNR ternyata dapat disimpulkan bahwa semakin besar nilai PSNR, maka hasli pemrosesan citra semakin bagus atau semakin mendekati citra aslinya. 


\section{DAFTAR PUSTAKA}

[1]. A Cheddad, J. Condell, K. Curran, and P. M. Kevitt, "Biometric Inspired Digital Image Steganography," in 15th Annual IEEE International Conference and Workshop on the Engineering of Computer Based Systems (ecbs 2008), 2008, pp. 159-168.

[2]. Andono, P. N, dkk. (Pengolahan Citra Digital). Semarang. Penerbit Andi. Hal 77.

[3]. Gan, M. D.2003." Chameleon Image Steganography".Tehnical Paper, hal 1-8.

[4]. Hmood, Ali K. 2010. "On the accuracy of hiding information metrics: Counterfeit protection for education and important certificates". International Journal of the Physical Sciences, Vol. 5(7), hal 1054-1062. 